\title{
Synthesis and Characterization of Cholesteric Thermotropic Liquid Crystalline Polyesters Based on Isosorbide
}

\author{
Nayaku N. Chavan \\ Polymer Science and Engineering Division, National Chemical Laboratory, Pune, India. \\ Email: nn.chavan@ncl.res.in
}

Received July 23 $3^{\text {rd }}, 2011$; revised August 20 $0^{\text {th }}, 2011$; accepted September $27^{\text {th }}, 2011$.

\begin{abstract}
Background: Generally main chain cholesteric thermotropic liquid crystalline polymers are prepared form chiral diacid or diol monomer. But these monomers are costly. Isosorbide is chiral cycloaliphatic diol accessible from renewable resources in the form of pure enantiomers. Thus it is used to synthesize main chain cholesteric thermotropic liquid crystalline polymers. Incorporation of phenyl hydroquinone into the backbone of the main chain frustrates chain packing, thus lowering the crystallinity and depressing the melting point below the degradation temperature, also improves the solubility due to disruption of packing and maintains the mechanical and thermal performance. Results: Optical microscopy study reveals that more than 50\% of isosorbide content with phenyl hydroquinone and terephthalic acid showed "yellow iridescent oily streaks" with a background of mosaic/marble texture. These are the typical textures of cholesteric liquid crystalline phase. Copolyesters based on phenyl hydroquinone, isosorbide and terephthalic acid are soluble in aprotic solvents like N,N-dimethylacetamide (DMAC), dimethyl sulfoxide (DMSO), N,N-dimethylformamide $(D M F)$, and N-methyl-2-pyrrolidone (NMP). Solubility increases with the content of isosorbide percent. Thermal stability of all copolyesters was more than $300^{\circ} \mathrm{C}$ on the basis of $10 \mathrm{wt} \%$ loss. Conclusions: It was found that main chain cholesteric thermotropic liquid crystalline polymers can be prepared form chiral cycloaliphatic diol such as isosorbide. Main chain cholesteric thermotropic liquid crystalline polyesters are prepared from phenyl hydroquinone, isosorbide and terephthalic acid showed thermal stability more than $300^{\circ} \mathrm{C}$. Main chain cholesteric thermotropic liquid crystalline polymers are soluble in aprotic solvents like DMAC, DMSO, DMF and NMP.
\end{abstract}

Keywords: Liquid Crystalline Polymers, Thermotropic, Cholesteric, Differential Scanning Calorimetry, Optical Microscopy, Thermo Gravimetric Analysis, Wide Angle X-Ray Diffraction, Crystallinity, Inherent Viscosity, Solubility and Solution Polycondensation

\section{Introduction}

Cholesteric liquid crystalline polymers (ChLCPs) have ability to produce supermolecular structures characterized by a helical organization with certain identity period. This special organization is responsible for unique optical properties of cholesteric polymer liquid crystals such as selective reflection of light at different wavelengths, very high optical activity, high sensitivity of selective reflection of light to temperature variations and to the action of external electrical and magnetic fields [1-5]. The requirement of principal condition to develop a cholesteric phase is associated with the presence of an chiral (asymmetric) center in monomer which produces a heli- cal supermolecular structure [6]. Cholesteric phase is characterized by circular dichroism: the light selective reflected by cholesteric liquid crystal is circularly polarized. The direction of circular polarization of the reflected beam coinsides with the direction of the twisting of cholesteric helix. The principal feature of cholesteric structure is associated with a strong rotation of polarization plane, which may be as high as $10^{4} \mathrm{deg} \cdot \mathrm{mm}^{-1}$. In conventional organic liquids this parameter is provided by only chirality of molecules and it does not exceed $10^{2}$ $\operatorname{deg} \cdot \mathrm{mm}^{-1}$. The helical ordering is a result of the frustration between molecular chirality and layer ordering and is unusual in the fact that the twist is manifested by a regular array of screw dislocations. High sensitivity of 
the pitch of the helix changes with respect to temperature as well as the action of electrical and magnetic fields offers substantial advantages for practical applications of such $\mathrm{ChLCPs}$ are as thermometers and thermoindicators for techniques and medicine.

To prepare ChLCPs different polymerization methods are applied: 1) homopolymerization of chiral mesogenic monomers; 2) copolymerization of nematogenic monomers with the chiral mesogenic monomers; 3) copolymerization of chiral mesogenic monomers with nonmesogenic monomers. The most advantageous procedure for the development of cholesteric mesophase is copolymerization of mesogenic and chiral monomers. This approach offers a convenient means for the preparation of the cholesteric copolymers and allows one to control phase and optical properties of cholesteric polymer by varying their composition [7-9]. Addition of flexible aliphatic spacer increases solubility but simultaneously it reduces the thermal and mechanical performance of polymers. According to structure property relationship study terephthalic acid is highly rigid diacid based monomer and it enhances performance of polymers due to para-para orientation. Hydroquinone is also highly rigid diol based monomer and it improves performance of polymers due to para-para orientation. Homopolymer of hydroquinone and terephthalic acid is insoluble due to highly integrated para-para orientation. Incorporation of aromatic unit such as phenyl group on the backbone of the main chain frustrates chain packing, thus lowering the crystallinity and depressing the melting point below the degradation temperature, also improves the solubility due to disruption of packing and maintains the mechanical and thermal performance [10].

Prime aim of the study was to synthesize high performance main chain cholesteric thermotropic liquid crystalline polyesters using an isosorbide as chiral cycloaliphatic diol. Isosorbide is an attractive building block because it is easily accessible from renewable resources in the form of pure enantiomers [11-15]. It is well known that aliphatic spacer reduces thermal and mechanical performance of polymers. Hence it is not advisable to use aliphatic spacer even though it improves solubility. Isosorbide structure contains two cycloaliphatic rings and ether bridges. It improves the rigidity as well as performance of polymers due to cycloaliphatic group. In our earlier communication isosorbide based main chain cholesteric thermotropic liquid crystalline polyesters were reported [5].

In this communication, we attempted to use an isosorbide as chiral building block to prepare main chain cholesteric thermotropic liquid crystalline polyesters. Thermal, spectral, mesomorphic and physical properties of polyesters were characterized by thermogravimetric ana- lysis (TGA), ${ }^{1} \mathrm{H}$ nuclear magnetic resonance $\left({ }^{1} \mathrm{H}\right.$ NMR), polarizing optical microscopy (POM), wide angle X-ray diffraction (XRD), solubility and inherent viscosity. The influence of the concentration of the chiral monomer on cholesteric thermotropic liquid crystalline phase behavior of the polyesters is discussed.

\section{Experimental}

\subsection{Materials}

Phenyl hydroquinone purchased from Aldrich and was recrystallized from chloroform. Terephthalic acid received from Sisco and was used as received. Thionyl chloride procured from Loba and was distilled prior to use. Isosorbide received from Aldrich and was used as such. Benzyl triethyl ammonium chloride (BTEAC) purchased from Spectrochem and was used without purification. Analytical reagent grade sodium hydroxide received from Merck and was used as received. Dichloromethane procured from Merck and was distilled over calcium hydride. Dimethylacetamide (DMAC) purchased form Aldrich and was distilled under reduced pressure on calcium hydride.

\subsection{Measurements}

Inherent viscosities of copolyesters were measured at a concentration of $0.5 \mathrm{dL} / \mathrm{g}$ in dimethyl acetamide using an Ubbelhode viscometer at $30^{\circ} \mathrm{C} .{ }^{1} \mathrm{H}$ NMR spectra were recorded on a Brucker AC300 spectrometer at room temperature in deuterated solvents. Thermo gravimetric analyses (TGA) were carried out on Perkin Elmer TGA-7 model under $\mathrm{N}_{2}$ atmosphere using heating rate of 10 ${ }^{\circ} \mathrm{C} / \mathrm{min}$. The optical characterization was performed on a Mettler polarizing optical microscope equipped with a FP2 Mettler hot stage, at magnification of 50X. Wide angle $\mathrm{x}$-ray scattering (WAXS) curves were obtained by a Philips PW X-ray diffractometer equipped with 1830 generator and 1710 adjustment with $\mathrm{CuK} \alpha$ radiation 1.54 $\AA$.

\subsection{Polymerization (Solution Method)}

Into three necked $100 \mathrm{~mL}$ round bottom flask, equipped with high speed mechanical stirrer, ice bath etc., phenyl hydroquinone $(1.0 \mathrm{~g}, 5.3 \mathrm{mmol})$ and sodium hydroxide solution $(14 \mathrm{~mL}, 10.6 \mathrm{mmol})$ were added. The solution was stirred for $15 \mathrm{~min}$ at room temperature. BTEAC (20 $\mathrm{mg}$ ) added and the solution was cooled to $5^{\circ} \mathrm{C}$. To this solution $10 \mathrm{~mL}$ dichloromethane containing terephthaloyl chloride (1.076 g, $5.3 \mathrm{mmol})$ was added at once. The solution vigorously stirred at $2000 \mathrm{rpm}$ for $30 \mathrm{~min}$ and polymeric solution was poured into hot water. Filtered the solution and washed with methanol for several times. Polymer obtained was dried under reduced pressure at 


\section{$80^{\circ} \mathrm{C}$ for $8 \mathrm{~h}$.}

\section{Results and Discussion}

Chiral polymers have been attracting much more interest because of their chirooptical and stereospecific properties. The synthesis of cholesteric liquid crystalline polyesters was performed with sugar diol such as isosorbide an attractive chiral building block. Several isotropic polyesters of this cycloaliphatic diol were synthesized by other research groups [11-15].

Synthesis of cholesteric thermotropic liquid crystalline polyesters from phenyl hydroquinone, isosorbide and terephthalic acid is depicted in Scheme 1 and compositions used for the syntheses of copolyesters are listed in Table 1. Polycondensation was performed by interfacial polymerization method using BTEAC as a phase transfer catalyst at $5^{\circ} \mathrm{C}$.

\subsection{Solubility}

Solubility of cholesteric liquid crystalline polymers based on phenyl-hydroquinone, isosorbide and terephthalic acid are reported in Table 2. All these cholesteric thrmeotropic liquid crystalline polyesters were insoluble in common organic solvent like chloroform due to high rigidity
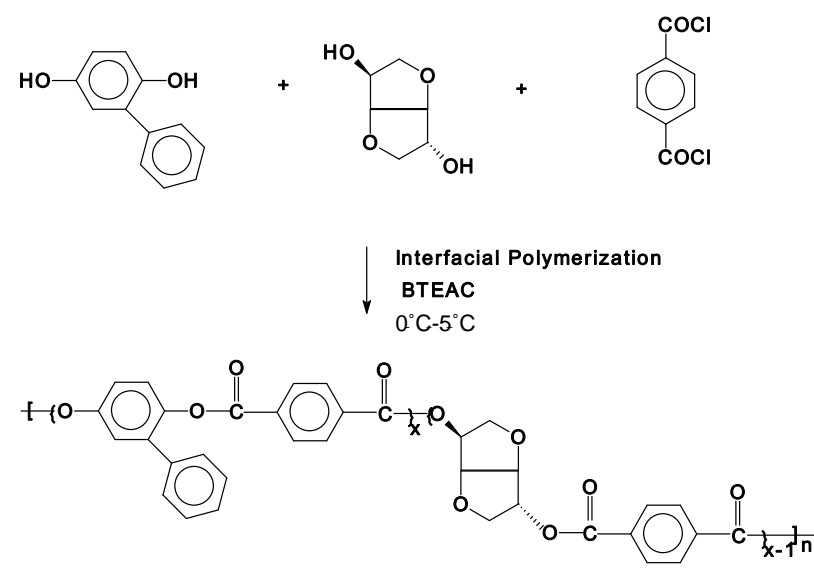

Scheme 1. Synthesis of cholesteric thermotropic liquid crystalline polyesters based on phenyl hydroquinone, isosorbide and terephthaloyl chloride.

Table 1. Compositions of copolyesters based on phenyl-hydroquinone, isosorbide and terephthaloyl chloride.

\begin{tabular}{|c|c|c|c|c|c|c|}
\hline Polymer code & ph-Hq:Iso:TPCl (Compositions) & ph-Hq (mmol) & Isosorbide (mmol) & TPCl (mmol) & $\mathrm{NaOH}(\mathrm{mmol})$ & BTEAC (mg) \\
\hline NNC-1 & 100:00:100 & 5.300 & - & 5.300 & 10.600 & 20 \\
\hline NNC-2 & $85: 15: 100$ & 4.505 & 0.795 & 5.300 & 10.600 & 20 \\
\hline NNC-3 & $70: 30: 100$ & 3.710 & 1.590 & 5.300 & 10.600 & 20 \\
\hline NNC-4 & $50: 50: 100$ & 2.650 & 2.650 & 5.300 & 10.600 & 20 \\
\hline NNC-5 & $35: 65: 100$ & 1.855 & 3.445 & 5.300 & 10.600 & 20 \\
\hline NNC-6 & $20: 80: 100$ & 1.060 & 4.240 & 5.300 & 10.600 & 20 \\
\hline NNC-7 & $00: 100: 100$ & - & 5.300 & 5.300 & 10.600 & 20 \\
\hline
\end{tabular}

ph-Hq = phenyl-Hydroquinone; Iso = Isosorbide; $\mathrm{TPCl}=$ Terephthaloyl chloride; $\mathrm{BTEAC}=$ Benzyl triethyl ammonium chloride; $\mathrm{NaOH}=\mathrm{Sodium}$ hydroxide .

Table 2. Solubility of liquid crystalline homo/copolymers based on phenyl-hydroquinone, isosorbide and terephthaloyl chloride.

\begin{tabular}{|c|c|c|c|c|c|}
\hline \multirow{2}{*}{ Polymer code } & \multicolumn{5}{|c|}{ Solvent } \\
\hline & $\mathrm{CHCl}_{3}$ & DMAc & DMSO & DMF & NMP \\
\hline NNC-1 & - & - & - & - & - \\
\hline NNC-2 & - & - & - & + & + \\
\hline NNC-3 & - & + & - & + & + \\
\hline NNC-4 & - & + & + & + & + \\
\hline NNC-5 & - & + & + & + & + \\
\hline NNC-6 & - & + & + & + & + \\
\hline NNC-7 & - & + & + & + & + \\
\hline
\end{tabular}

$+=$ soluble at room temperature; $-=$ insoluble at room temperature. 
of the structure.

Solubility of cholesteric thermotropic liquid crystalline copolyesters was tested in aprotic solvents like dimethyl acetamide (DMAC), dimethyl sulphoxide (DMSO), dimethyl formamide (DMF) and N-methyl-2-pyrrolidone (NMP). Solubility increases with isosorbide content [5, 16]. Homopolymer based on phenyl hydroquinone and terephthalic acid is insoluble in chloroform as well in aprotic solvents like DMAC, DMSO, DMF and NMP. It clearly indicates that introduction of phenyl ring on hydroquinone does not improve solubility in aprotic solvents also. Homopolymer of isosorbide and terephthalic acid is also insoluble in chloroform. It dictates that isosorbide contain cycloaliphatic ring which acts as rigid moiety. Incorporation of terephthalic acid increases ridigity due to para-para orientation and reduces solubility of homopolyestser also.

\subsection{Thermal Properties}

The thermo gravimetric analyses (TGA) of cholesteric liquid crystalline copolymers based on phenyl-hydroquinone, isosorbide and terephthaloyl chloride are summarized in Table 3. Thermo gravimetric analyses (TGA) of cholesteric liquid crystalline copolyesters were determined in nitrogen atmosphere using $10^{\circ} \mathrm{C} / \mathrm{min}$ heating rate. Higher the molar fraction of phenyl hydroquinone stabilizes cholesteric liquid crystalline phase and rises the isotropization temperature above $300^{\circ} \mathrm{C}$. TGA thermogram of NNC-1 showed $5 \mathrm{wt} \%$ loss at $350^{\circ} \mathrm{C}$ and $10 \mathrm{wt} \%$ loss at $395^{\circ} \mathrm{C}$. DTG curve of the same polyester showed no decomposition up to $375^{\circ} \mathrm{C}$ and maximum decomposition was at $509^{\circ} \mathrm{C}$. TGA thermogram of NNC-2 showed maximum wt. loss at $536^{\circ} \mathrm{C}$, but DTG peak was broad. The $\mathrm{T}_{\max }$ temperature was on higher side due to the broadness of DTG peak. All copolyesters showed two stage degradation. It clearly indicates that liquid crystal- line phases are formed. Homopolyester based on isosorbide and terepathalic acid showed first stage degradation above $300^{\circ} \mathrm{C}$ due to degradation of ether linkages of isosorbide and second stage degradation above $400^{\circ} \mathrm{C}$ due to degradation of polymeric unit.

Thermal stability decreases with isosorbide content increase. It is due to two ether linkages are present in isosorbide unit. Bridging group like ether degrade faster than aromatic ring due to bond energy of $\mathrm{C}=\mathrm{C}(145 \mathrm{kcal} / \mathrm{mol})$ is higher than $\mathrm{C}-\mathrm{O}$ linkage $(78 \mathrm{kcal} / \mathrm{mol})$. The thermal stability of all copolyesters was more than $300^{\circ} \mathrm{C}$ on the basis of $10 \%$ wt. loss. Even though $10 \mathrm{wt} \%$. loss of homopolyester based on isosorbide and terephthalic acid (NNC-7) was at $299^{\circ} \mathrm{C}$. It clearly indicates that homopolyester based on isosorbide and terephthalic acid is also highly thermally stable. Maximum decomposition temperature $\left(\mathrm{T}_{\max }\right)$ decreases with isosorbide content increase.

\subsection{Inherent Viscosity}

Inherent viscosities of liquid crystalline copolyesters were determined in dimethyl acetamide (DMAC) at $30^{\circ} \mathrm{C}$ using $0.5 \%$ concentration in Ubbelhode viscometer. Polyester NNC-1 and NNC-2 are insoluble in DMAC. Inherent viscosities of liquid crystalline copolyesters were in the range of 0.11 to $0.15 \mathrm{dL} / \mathrm{g}$. It indicates that molecular weights of copolyesters were not high. It may be due to interfacial polycondensation method is not suitable for the polymerization of isosorbide with acid chloride in the presence of strong base like sodium hydroxide. During interfacial polycondensation, isosorbide containing ether linkages may not be stable and lead to imbalance the stoichiometry of diols to acid chloride ratio. Polycondensation of diols with acid chlorides may be carried out with weak base like pyridine, and solution polycondensation may be carried out at high temperature using toluene or o-dichlorobenzene as solvent [5].

Table 3. Physical properties of liquid crystalline homo/copolymers based on phenyl-hydroquinone, isosorbide and terephthaloyl chloride.

\begin{tabular}{|c|c|c|c|c|c|}
\hline Polymer code & $\mathrm{T}_{5}\left({ }^{\circ} \mathrm{C}\right)$ & $\mathrm{T}_{10}\left({ }^{\circ} \mathrm{C}\right)$ & $\mathrm{T}_{\max }\left({ }^{\circ} \mathrm{C}\right)$ & $\eta_{\text {inh }}{ }^{a}(d L / g)$ & Crystallinity (\%) \\
\hline NNC-1 & 350 & 395 & 509 & $\mathrm{~b}$ & 31.17 \\
\hline NNC-2 & 301 & 330 & 536 (broad peak) & $\mathrm{b}$ & 37.81 \\
\hline NNC-3 & 286 & 362 & 514 & 0.15 & 28.37 \\
\hline $\mathrm{NNC}-5$ & 299 & 321 & 512 (broad peak) & 0.13 & 33.71 \\
\hline NNC-6 & 344 & 369 & 464 & 0.12 & 33.44 \\
\hline NNC-7 & 272 & 299 & 418 & 0.11 & 37.62 \\
\hline
\end{tabular}

$\mathrm{T}_{5}=5 \mathrm{wt} \%$ loss, $\mathrm{T}_{10}=10 \%$ weight loss; $\mathrm{T}_{\max }=$ maximum decomposition; $\mathrm{a}=$ inherent viscosity determined in $\mathrm{DMAC}$ at $30^{\circ} \mathrm{C} ; \mathrm{b}=$ insoluble in $\mathrm{DMAC}$. 


\section{4. ${ }^{1} \mathrm{H}$ NMR Spectrum}

${ }^{1} \mathrm{H}$ NMR spectrum of isosorbide was carried out in $\mathrm{CDCl}_{3}$ and is presented in Figure 1. The protons of isosorbide are observed in $3.50-4.75 \delta \mathrm{ppm}$ range and hydroxyl protons are observed at 2.45 and $5.58 \delta \mathrm{ppm} .{ }^{1} \mathrm{H}$ NMR spectrum of cholesteric thermotropic liquid crystalline copolyester NNC-4 in deuterated DMSO based on phenyl hydroquinone:isosorbide:terephthaloyl chloride (50:50:100) is presented in Figure 2. It showed that the incorporation of isosorbide protons which are observed at $4.0-5.5 \delta$ ppm range. The position of hydroxyl groups also shifted. It clearly indicates that the copolymer formation. The intensity of isosorbide peaks was low because inherent viscosities of these copolyesters were low.

\subsection{Optical Microscopy}

Higher concentrations of phenyl hydroquinone like $85 \%$ or $100 \%$ did not melt up to $350^{\circ} \mathrm{C}$ on polarizing microscope, hence photomicrographs were not performed. The most interesting textures of cholesteric phase observed for copolymer NNC-5 and NNC-6 and are presented in Figures 3-10. It clearly showed "yellow iridescent oily streaks" having a background of mosaic texture which is a special characteristic of cholesteric liquid crystalline phase.

Optical textures of copolyester NNC-5 at 245, 273, and $297^{\circ} \mathrm{C}$ were depicted in Figures 3-5 respectively. It showed "yellow iridescent streak" with background of mosaic texture, which is a typical texture of cholesteric phase. Optical texture of polymer NNC-5 at $297^{\circ} \mathrm{C}$ depicted in Figure 5. It showed "yellow broad and bright oily streak" with background of mosaic texture, which is also a typical texture of cholesteric phase. Copolyesters NNC-5 showed broad range of cholesteric liquid crystalline phase i.e. $245^{\circ} \mathrm{C}-297^{\circ} \mathrm{C}$. Optical texture of copolymer NNC-5 at $315^{\circ} \mathrm{C}$ was illustrated in Figure 6 and it showed "yellow broad blackish oily streak" with background of mosaic texture. It clearly indicates the initiation of degradation of cholesteric phase.

Optical textures of copolyester NNC-6 at $174^{\circ} \mathrm{C}$, $184^{\circ} \mathrm{C}, 198^{\circ} \mathrm{C}$, and $231^{\circ} \mathrm{C}$ are depicted in Figures 7-10. Optical texture of copolyester NNC-6 at $174^{\circ} \mathrm{C}$ showed "small yellow oily streak" having a background of marble texture indicates the initiation of formation of cholesteric phase. Optical textures of copolyester NNC-6 at

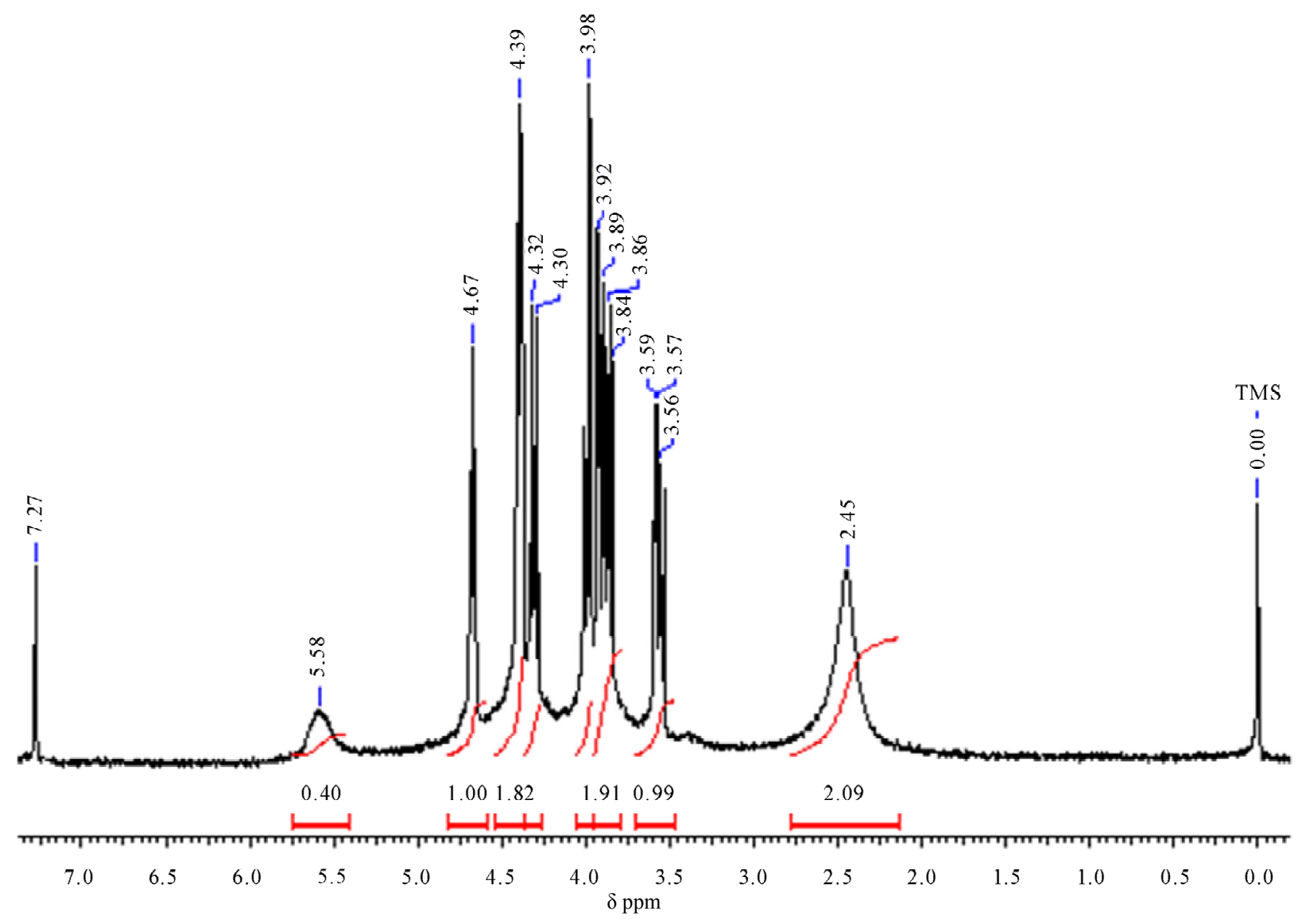

Figure 1. ${ }^{1} \mathrm{H}$ NMR spectrum of Isosorbide. 


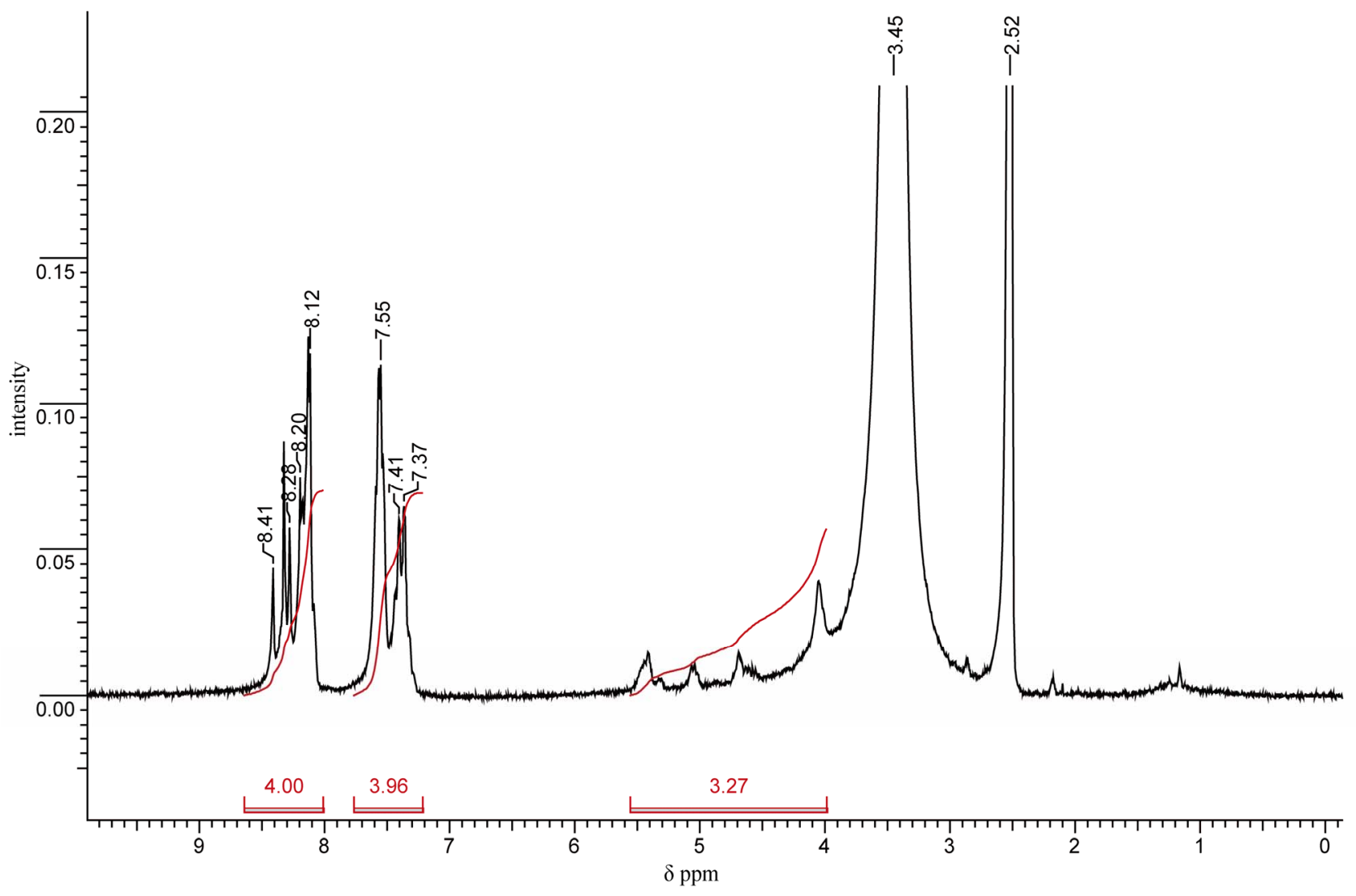

Figure 2. ${ }^{1} \mathrm{H}$ NMR spectrum of copolyester NNC-4 [ph-HQ:Isosorbide:TPC (50:50:100)].

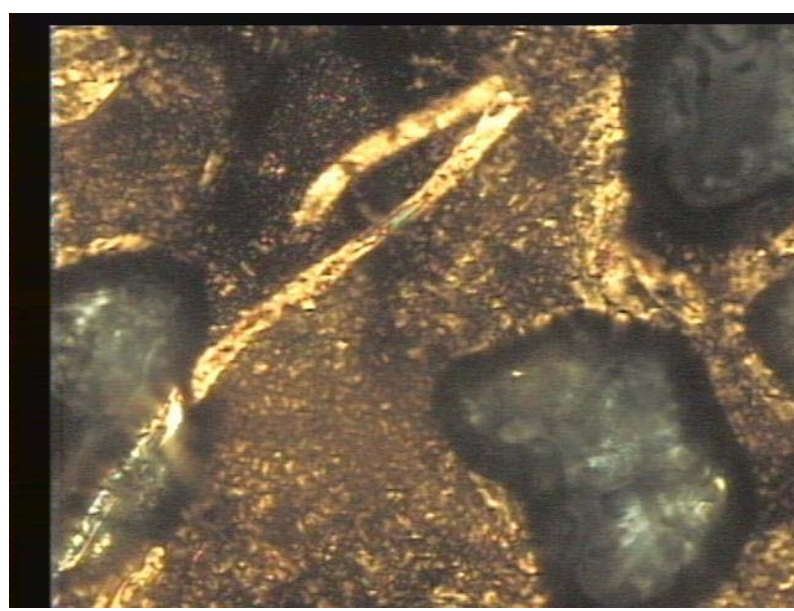

Figure 3. Optical texture of copolyester NNC-5 at $245^{\circ} \mathrm{C}$.

$184^{\circ} \mathrm{C}$ and $198^{\circ} \mathrm{C}$ showed "broad yellow oily streaks" with background of mosaic texture. It indicated that the broad range of cholesteric liquid crystalline phase i.e. $174^{\circ} \mathrm{C}-231^{\circ} \mathrm{C}$. Optical texture of polymer NNC-6 at $231^{\circ} \mathrm{C}$ is depicted in Figure 10. It showed blackish "yellow iridescent oily streaks" with background of marble texture, which is a typical character of initiation of degradation. Homopolyester of isosorbibe with terephthalic

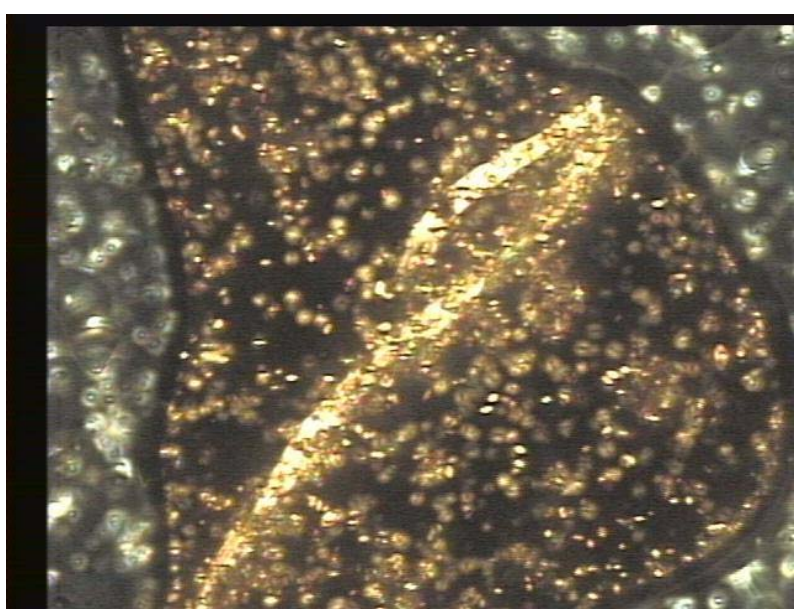

Figure 4. Optical texture of copolyester NNC-5 at $273^{\circ} \mathrm{C}$.

acid did not show cholesteric liquid crystalline texture due to depression of the liquid crystalline orientation order. All the optical photomicrographs were performed on heating cycle of optical microscope using magnification $50 \times$.

\subsection{Crystallinity}

Crystallinity percentage of cholesteric liquid crystalline 


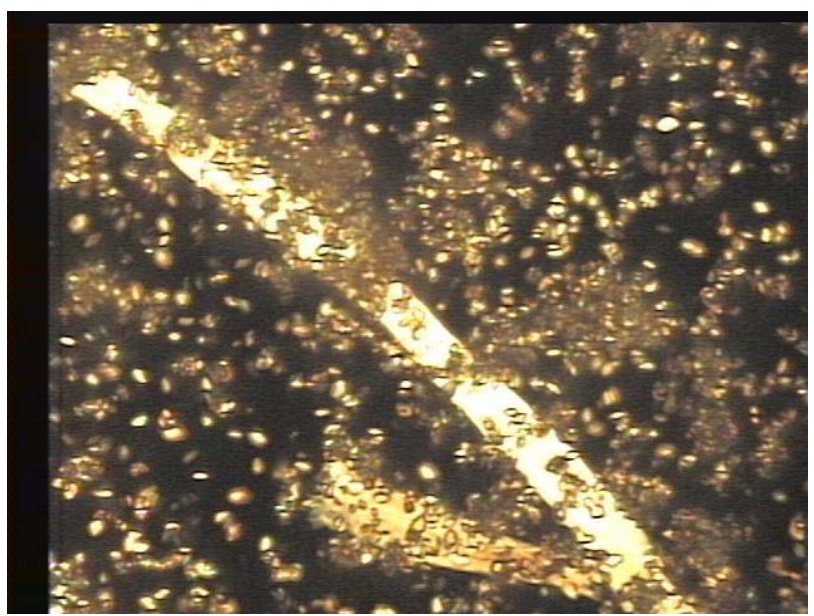

Figure 5. Optical texture of copolyester NNC-5 at $297^{\circ} \mathrm{C}$.

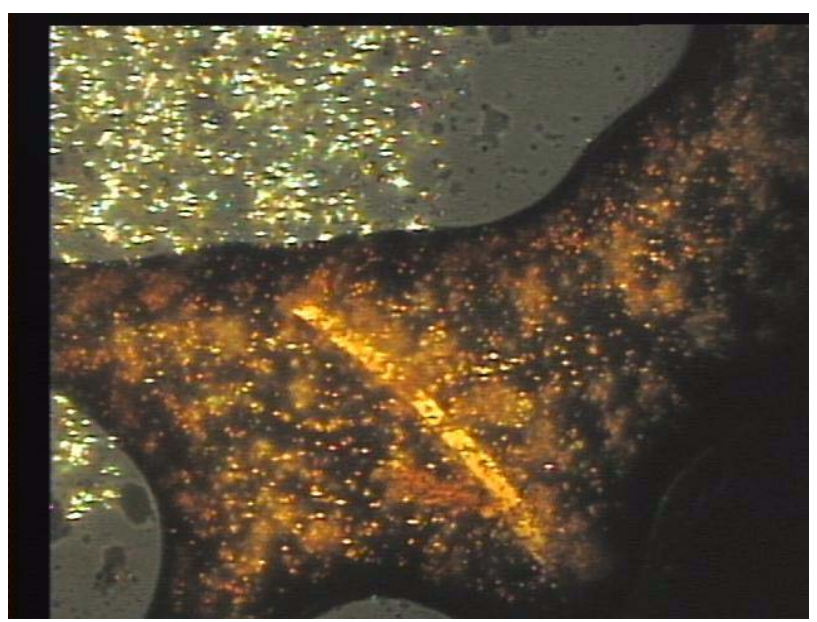

Figure 6. Optical texture of copolyester NNC-5 at $315^{\circ} \mathrm{C}$.

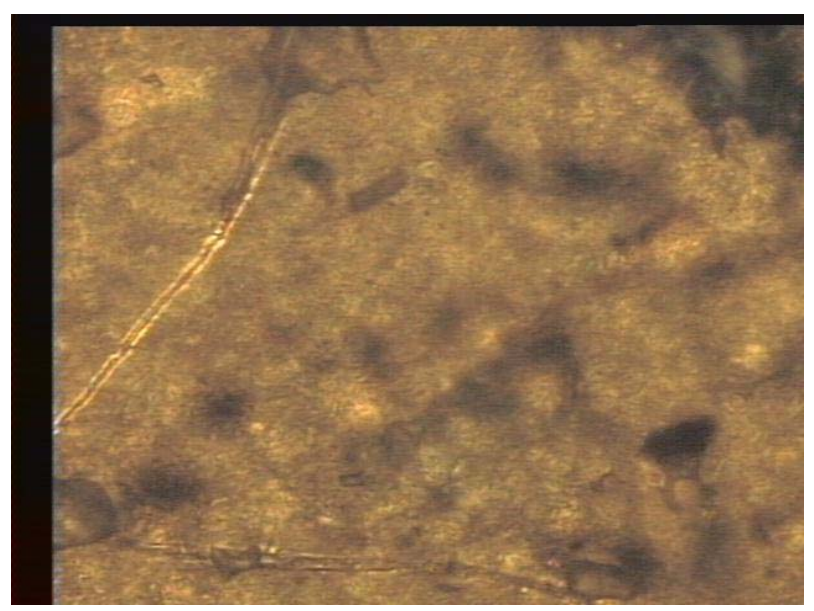

Figure 7. Optical texture of copolyester NNC-6 at $174^{\circ} \mathrm{C}$.

copolyesters was in the range was 31.17 to 38.75 . It shows that copolyesters are semicrystalline. The WAXD patterns did not show definite trend.

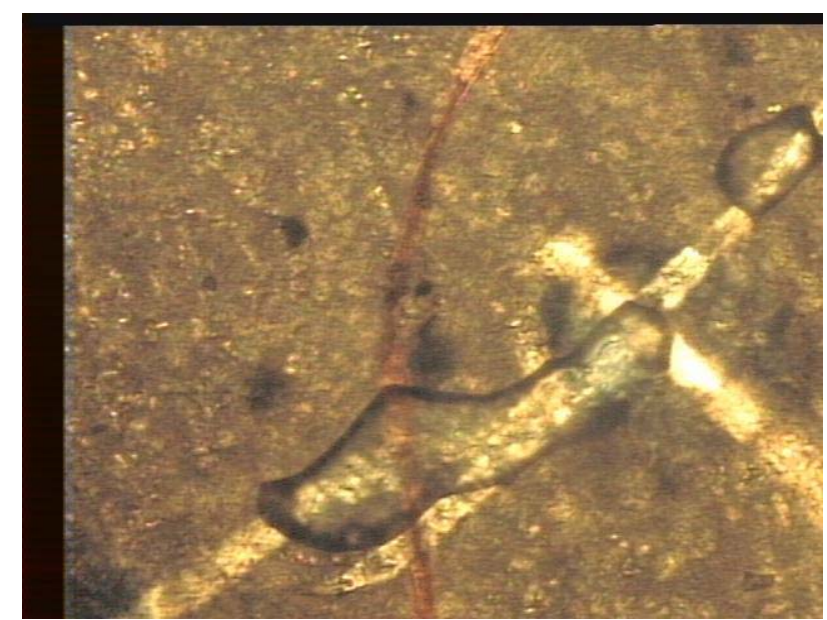

Figure 8. Optical texture of copolyester NNC-6 at $184^{\circ} \mathrm{C}$.

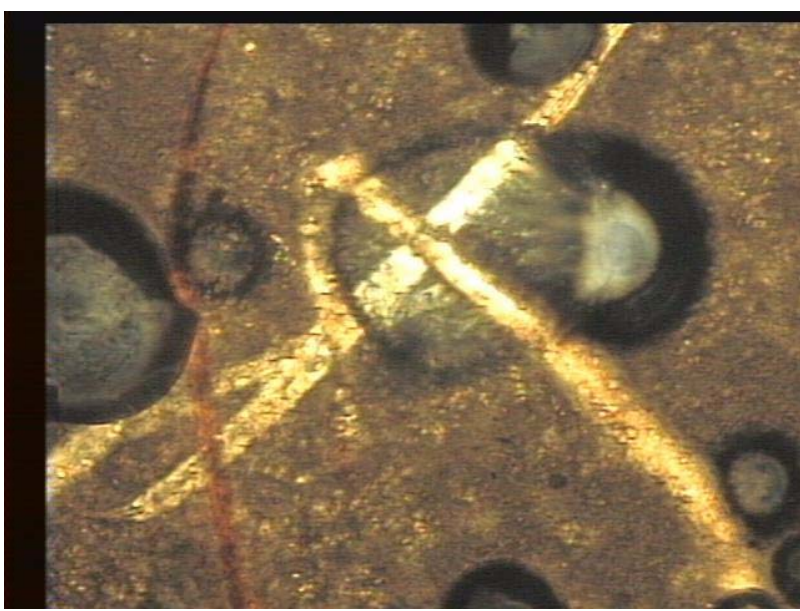

Figure 9. Optical texture of copolyester NNC-6 at $198^{\circ} \mathrm{C}$.

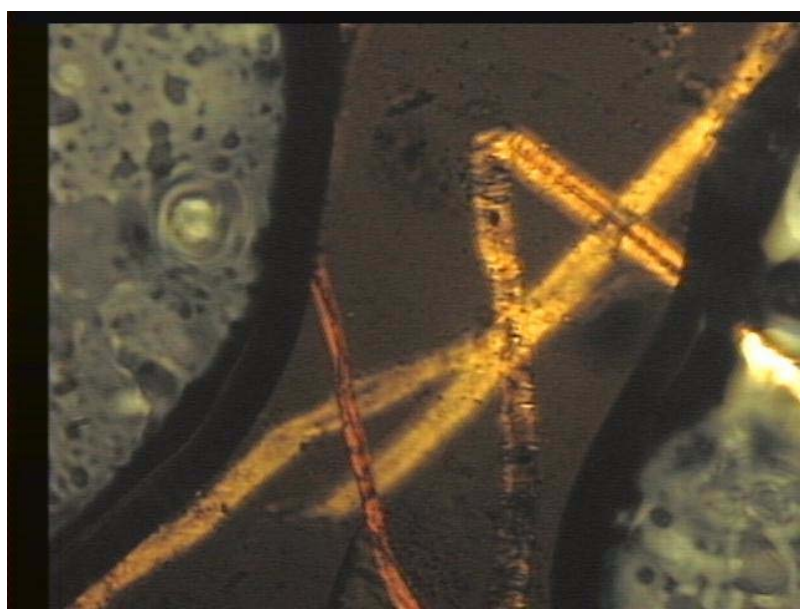

Figure 10. Optical texture of copolyester NNC-6 at $231^{\circ} \mathrm{C}$.

\section{Conclusions}

The present study allows the conclusion that the choles- 
teric thermotropic liquid crystalline polyesters can be synthesized from isosorbide, phenyl hydroquinone and terephthalic acid. Isosorbide is an optically active and inexpensive cycloaliphatic diol. Due to its cycloaliphatic nature it helps to increase the performance cholesteric thermotropic liquid crystalline polyesters. Homopolyester of isosorbide and terephthalic acid is thermally stable up to $300^{\circ} \mathrm{C}$. Copolyesters based on isosorbide, phenyl hydroquinone and terephthalic acid showed thermal stability more than $300^{\circ} \mathrm{C}$ on the basis of $10 \mathrm{wt} \%$ loss. Optical microscopy study reveals that more than $50 \%$ of isosorbide content with phenyl hydroquinone and terephthalic acid showed "yellow iridescent oily streaks" with a background of mosaic/marble texture. These are the typical textures of cholesteric liquid crystalline phase.

Interfacial polymerization method is not suitable to get high molecular weight polyesters, because isosorbide containing two ether linkages may not be stable with strong inorganic base like sodium hydroxide lead to imbalance the stoichiometry of diols to acid chloride ratio. High performance cholesteric liquid crystalline polyesters with high molecular weight will be synthesized from same monomers by solution polycondensation method using weak organic base.

\section{REFERENCES}

[1] V. Shibaev, A. Bobrovsky and N. Boiko, "Photoactive Liquid Crystalline Polymer Systems with Light-Controllable Structure and Optical Properties," Progress in Polymer Science, Vol. 28, No. 5, 2003, pp. 729-836. doi:10.1016/S0079-6700(02)00086-2

[2] S. Nakanishi and M. Ueda, "Synthesis of Novel Glass-Forming Liquid Crystals Containing Acrylic Acid Trimer Core Unit and Mesogenic Moiety, and Their Use in Cholesteric Reflection Films," Polymer Journal, Vol. 39, No. 3, 2007, pp. 252-258. doi:10.1295/polymj.PJ2006115

[3] B. Zhang, J. Hu, B. Wang, D. Yao and H. Li, "Synthesis and Characterization of Side-Chain Cholesteric Elastomers Derived from an Isosorbide Cross Linking Agent," Colloid \& Polymer Science, Vol. 285, No. 15, 2007, pp. 1683-1690. doi:10.1007/s00396-007-1742-5

[4] J. Lub, W. P. M. Nijssen, R. T. Wegh, J. P. A. Vogels and A. Ferrer, "Synthesis and Properties of Photoisomerizable Derivatives of Isosorbide and Their Use in Cholesteric Filters," Advanced Functional Materials, Vol. 15, No. 12, 2005, pp. 1961-1972. doi:10.1002/adfm.200500127

[5] S. A. Jadhav, R. R. Chougule, Y. A. Shinde and N. N. Chavan, "Synthesis and Characterization of Cholesteric Thermotropic Liquid Crystalline Polyesters," Journal of Applied Polymer Science, Vol. 103, No. 2, 2007, pp. 1232-1237. doi:10.1002/app. 24610

[6] H. Finklemenn, H. Ringsdorf, W. Siol and J. H. Wendorff, "Synthesis of Cholesteric Liquid Crystalline Polymers," Macromolecular Chemistry, Vol. 179, No. 3, 1978, pp.

\section{9-832. doi:10.1002/macp.1978.021790326}

[7] J. Asrar, J. Toriumi, J. Watanabe, W. R. Krigbaum, A. Ciferri and J. Preston, "Thermotropic Homopolyesters. I. The Preparation and Properties of Polymers Based on 4,4'-Dihydroxybiphenyl," Journal of Polymer Science Polymer Part B: Physics Edition, Vol. 21, No. 7, 1983, pp. 1119-1131. doi:10.1002/pol.1983.180210712

[8] K. Fujishiro and R. W. Lenz, "Main-Chain Cholesteric Liquid Crystalline Polyesters with Chiral Pendant Groups. 1. Model Compounds and Polyesters Containing a Chiral Substituted Hydroquinone," Macromolecules, Vol. 25, No. 1, 1992, pp. 81-87. doi:10.1021/ma00027a014

[9] H. Park, J. Jin and R. W. Lenz, "Liquid Crystal Polymers: 19. Cholesteric Main Chain Polyesters with Triad Aromatic Ester Mesogenic Units and Chiral Polyalkaline Spacers," Polymer, Vol. 26, No. 9, 1985, pp. 1301-1306. doi:10.1016/0032-3861(85)90303-9

[10] N. Khan, Z. Bashir and D. M. Price, "Liquid Crystalline Aromatic Polyesters Formed with Terephthalic Acid, Phenyl Hydroquinone, and Naphthalene or Anathracene Diols," Journal of Applied Polymer Science, Vol. 58, No. 9, 1995, pp. 1509-1516. doi:10.1002/app.1995.070580913

[11] H. R. Kricheldorf and N. Probst, "Liquid-Crystalline Polyimides. 16. Chiral Thermotropic Copoly(Ester-Imide)s Based on Isosorbide and N-(4-Carboxyphenyl) trimellitimide," Macromolecular Rapid Communications, Vol. 16, No. 4, 1995, pp. 231-237. doi:10.1002/marc.1995.030160401

[12] G. Schwarz and H. R. Kricheldorf, "New Polymer Synthesis. LXXXIII. Synthesis of Chiral and Cholesteric Polyesters from Silylated 'Sugar Diols'," Journal of Polymer Science Part A: Polymer Chemistry Edition, Vol. 34, No. 4, 1996, pp. 603-611. doi:10.1002/(SICI)1099-0518(199603)34:4<603::AID-P OLA6>3.0.CO;2-R

[13] H. R. Kricheldorf, S. Sun, A. Gerken and T. Chang, "Polymers of Carbonic Acid. 22. Cholesteric Polycarbonates Derived from (S)-((2-Methylbutyl)thio)hydroquinone or Isosorbide," Macromolecules, Vol. 29, No. 25, 1996, pp. 8077-8082. doi:10.1021/ma960494d

[14] Q. Lin, J. Pasatta and T. E. Long, "Synthesis and Characterization of Chiral Liquid-Crystalline Polyesters Containing Sugar-Based Diols via Melt Polymerization," Journal of Polymer Science Part A: Polymer Chemistry Edition, Vol. 41, No. 16, 2003, pp. 2512-2520. doi:10.1002/pola.10787

[15] B. Zhang, Y. Zheng and H. Lu, "Synthesis and Characterization of Side Chain Cholesteric Liquid Crystalline Polymers Containing Isosrbide as a Chiral Center," Liquid Crystals, Vol. 32, No. 3, 2005, pp. 357-364. doi:10.1080/02678290500034065

[16] M. Flugel and W. Heitz, "Synthesis and Properties of Polyamides Based on ( \pm )-Nonbornane-2 Endo, 3 Exo-Dicarboxylic Acid," Macromolecular Rapid Communications, Vol. 18, No. 6, 1997, pp. 523-528. doi:10.1002/marc.1997.030180611 